\title{
SEMIOTIC VISION OF IDEOLOGIES
}

\author{
J. Nescolarde-Selva \\ Department of Applied Mathematics. University of Alicante. Alicante. Spain. \\ J.L. Usó-Doménech \\ Department of Mathematics. University Jaume I. Castellón. Spain.
}

\begin{abstract}
A semiotic theory of systems derived from language would have the purpose of classifying all the systems of linguistic expression: philosophy, ideology, myth, poetry, art, as much as the dream, lapsus, and free association in a pluridimensional matrix that will interact with many diversified fields. In each one of these discourses it is necessary to consider a plurality of questions, the essence of which will only be comprehensible by the totality; it will be necessary to ask, in the first place, what will be the purpose of this language, what function does it fulfill and for which reason has it been constructed. The concept of world vision is introduced and its relation with Generalized Collective Conscience and Particularized Collective Conscience. Culture implies a particular World vision. Culture creates Generalized Collective Conscience. The semantic field is a structure that formalizes the units of a certain culture constituting a portion of the vision of the Reality that owns this culture. An ecological case is explained.
\end{abstract}

Keywords Circumstance, Code, Connotation, Culture, Semantic field, World vision

\section{INTRODUCTION}

Reality contains interpretable evidence, and the mental ways of communication and their extension, represented in the devices constructed by social man need to be understood. Language is an origin of the systemic conception of Reality. It is possible to define language as a symbolic substitute of Reality, or as a system of signs. Different classes of objects exist, and are characterized by different mental acts through which we distinguish them from their surroundings (Meinong, 1904). Objects of sensorial perception are different from objects of thought, but these latter ones are not less "objective" than the previous ones: they are apprehended by thought but not constituted by thought. According to the terminology of Meinong, meaning subsists, whereas the individual beings and the qualities exist. In this sense, objects of thought can be real without existing in the technical sense defined by Meinong. Mathematical objects are of this class. The first condition is (Agazzi, 1992) that these objects are there, and they are not made through an act of discourse, but through the presence of these objects in the Subject's thought. From a phenomenological viewpoint we may say that an object, simply by the fact of being present, offers the Subject an irrefutable witness of itself. The referential situation is the phenomenological presence of the object. And the truth of a sentence is the coincidence between the situation and its phenomenological presence. It is important to notice that meanings or understandings are only partially faithful with respect to any particular phenomenological presence or referential situation that they could denote. Some form of modalization (aletical, deontical or doxical) necessarily accompanies the communication. A great epistemological separation exists 
between thought and language. All organization of language depends on a complex structure. A bi-univocal correspondence between the perception of Reality and the linguistic system is unthinkable. The subject operates from a superior order, from a mesosystem that would include them and in which both appear like elements and not like closed and independent units. Horizontal forces on any system are those that determine their significance. This means that no language is neutral. And that no space of representation is neutral either. That is to say, the systemic conception, like any other semiotic conception, represents Reality in the same way as other nonsystemic conceptions.

Beings do not have an intrinsic meaning and they only transform themselves into signs when we have invested them with meaning. The signs are significant units that take their form from words, images, sounds, gestures and objects, studied within a system of semiotic signs, like meanings or code. In any process, we can distinguish between having a significant as an inherent property, and having significance when it is related to other processes of Reality that the Subject considers as a system. The existence of information is independent of the fact that there is a Subject able to decode the message, which it is intended to communicate. This objective information is termed significant. The information in a message acquires meaning if a Subject decodes the message. This subjective information is termed significance. (Sastre-Vazquez, P.. Usó-Doménech, J.L., Y. Villacampa, J. Mateu and P. Salvador. 1999; Usó-Domènech, J.L., G. Stübing, J. López-Vila, and P. Sastre Vázquez, 2002; Usó-Domènech, J.L., J. Mateu. 2004; Villacampa, Y., Usó-Domènech, J.L Mateu, J. Vives, F. and Sastre, P. 1999; Villacampa-Esteve, Y., Usó-Domènech, J.L., Castro-Lopez-M, A. and P. SastreVazquez, . 1999; Usó-Domènech, J.L. and Villacampa, Y., 2001).

Both distinctions involve the use of learned codes. The significance tends to emerge from an individual sign, until it is equipped with many meanings that go beyond what the sign says originally . Different orders of meaning or levels of significance exist:

1) The first order of significance is precisely the one of denotation, at which level there exists a sign $t$ consisting of significant and significance.

2) The connotation is a significance of the second order that uses the denotative sign (with significant and significance) as significant, with an additional associate significance.

The significance of a linguistic sign also depends on the code where it is located, since the codes give a scheme, compounded also by belief conventions, within which the linguistic sign acquires sense. This allows interpretation such as text interpretation (systems), each one of these being organized in agreement with codes and subcodes reflecting values, attitudes, beliefs, assumptions and practices. This implies a certain stability in the relations between significant and significance, restricting the amount of possible interpretations. This distinction considers the connotation as a sign that is 
derived from the significant of a denotative sign, so that the denotation takes us to a chain of connotations. Denotation is an underlying and primary significance.

The significant $\mathrm{S}$ or significance s depends entirely on the level in which the analysis operates. Then, what is significance in one level of the context, can be significant in another one.

The subject receives two types of semiotic stimuli:

a) The significant of the person's own processes or being.

b) The significant of the transmitted semiotic stimulus or the significant of the significance (connotation).

The significant coming from the sign becomes significance after passing through a filter or sieve, which we will denominate doxical filter. This filter consists of two essential components: language and the belief system.

Any conception of Reality, after passing through the doxical filter is a model, formal or not. The construction of such a model has inherently a language (formal or not) and the corresponding linguistic aspects such as the syntax and semantic components are something implicit. Due to the fact that grammar is a theory for a language and that every elaboration of a theory must include as its main objective ease and generality, it is natural to formulate a theory of linguistic structure which allows the most revealing general statements to take place (Chomsky, 1962).

\section{LANGUAGE AND WORLD VISION (WV)}

Conflict between two groups, including war, may be defined as a battle between belief systems. Symbols emerge strongly in such conflicts: they may be revered objects as stones, writings, buildings, flags or badges; whatever they may be, they may symbolize the central core of the belief system. When people become symbols, the real person may become obscured behind the projected symbolic image or person.

Organizations develop their own in-house culture and belief systems, too, which leads them to act and behave in ways that might not seem entirely rational to an outsider.

Societies and their associate phenomena, such as culture, language, literature, ethics, laws, economics, etc., can more adequately be understood and studied if they are regarded as systems. This be because networks of relations for any set of assumed observables allow examination of the ways the various socio-semiotic aggregates operate. 
Definition 1: By World Vision (WV) we understand a way to think, to hope, to project, to fear, to calculate, etc., of a human group, obligatory collective, immersed in a society characterized by a certain culture and in a determined historical period (Ferreras, 1980).

a) WV never is conceived, crystallized; their presences exist because they mediate and they inspire, but never appear in the perceived objective world.

b) All WV is a construction of a collective subject, since it is impossible to a single individual, to found, to build, to even express, everything in an imaginary system to be related, to think, to hope or to remember. Each group in its social life is constructing a precise, specific mentality that not only allows it to comply with the objective reality, but that also allows it to dream, to idealize, and to escape itself.

c) WV territory extends at the surface of the objective and at the depths of the subjective.

d) WV serves to live for living daily life, for the anodyne gesture and even to create a system of new connotations.

e) WV has an image of the world consciously or unconsciously perceived.

f) Before WV, there arises a series of social and historical manifestations, customs, beliefs, ideologies, projects, practices, gestures, etc.

We can distinguish between Generalized Collective Conscience (GCC) and Particularized Collective Conscience (PCC). GCC exists in society, time, history, etc., it is materially and necessarily in social, artistic, literary, etc. structures. PCC is the materialization and conceptualisation of GCC on the part of a group, class, clan, family, etc. Class conscience is, therefore, the taking of conscience on the part of a social group of the GCC. Therefore, the conscience of a class or group can be confused, until a certain point, with the Particularized Collective Conscience (PCC). It is the Individual Conscience (IC), that breaks with the PCC and it materializes in the GCC again. Complete autonomy does not exist, but exists when there is a break on the part of an individual conscience with a certain materialization of the GCC in PCC, and there is an 
attempt on the part of consciousness to form a new GCC. We can see the process of proceeding of the collective consciences in the following figure (Figure 1):

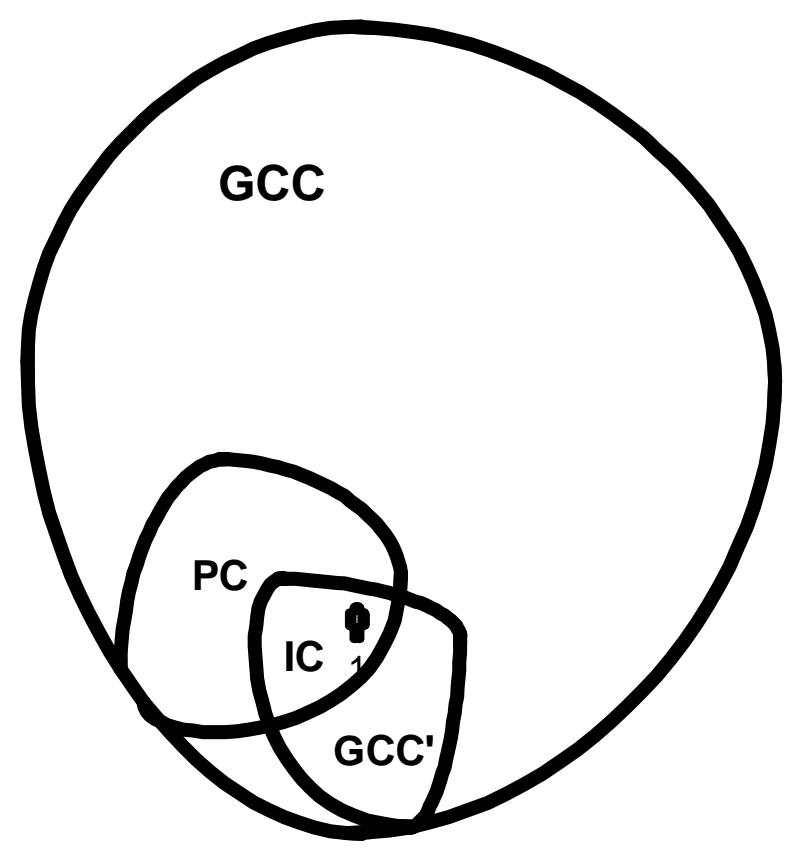

Figure 1.

Generalized Collective Conscience (GCC): It exists, it preexists, it is not conceptualised.

Particularised Collective Conscience (PCC): It is materialised by a group, class, clan, family, etc.

Individual Conscience (IC): It belongs to each particular individual.

IC opposes PCC with a new concept of GCC; for that reason, it is in the limit between the three-dimensional body of group PCC and the totality GCC. Therefore, an ideological exchange is a group rupture and the creation of new Generalised Collective Conscience (GCC').

Note 1: The Generalised Collective Conscience (GCC) only agrees with the Ideological Doxical Superstructure (IDS) in the case of monoideological societies.

Primitive or relatively isolated folk societies fulfil the condition specified in Note 1. 
All these divisions between different consciences try to establish and to construct relations, in order to find new explanations to the existence and operation of the collective conscience, only subject of the social structure forming the Structural Base (SB).

The individual subject (with his IC) is subject to the very strong influence of sociological factors (GCC and PCC), such as the structure of the language, the implicit or unconscious systems of social valuation, norms of communication, etc. That is to say, subject to the represented collective conscience like symbolic maps of reality. What an individual does with these symbolic maps is a phenomenon at the level of the ego, but their own symbolic maps correspond to GCC of a society. There exist an immense number of symbolic maps comprising the GCC, since it is here where are rooted social conventions like the structure and the linguistic syntax of a particular culture, its logic, deontic norms, popular ethics, religious vision, family structure, powerful taboos, rules of communication, games, and supposed general ideas about reality, etc. All those symbolic relations distinguish a particular society and all individuals interiorise them in greater or smaller degree by belonging to this society. Therefore, GCC represents the first massive accumulation of symbols in the IC.

All these deeply rooted symbolic maps fulfil, in essence, the same assignment; to advance and to mold the IC with the acceptable and significant conventional forms in their society (GCC and PCC). These conceptions mould perceptions, the individual learns, in effect, to conform and to translate reality in social terms shared with others. This is what it means: "to be a component of a society" (or culture, subculture, group, class, clan, family, etc.), since the individual becomes a member of his society (or equivalent) after satisfactorily interiorising the maps or sets of symbolic relations (GCC and PCC) constituting that society (or equivalent). The individual is included in the society when the society includes the individual (Wilber, 1977). This conventionalisation of reality requires individuals to learn to make a socially verifiable correspondence one to one between symbol and symbolized thing, world and its description. The individual must learn to associate specific objects with the conventionally correct words belonging to a certain language $\mathrm{L}$ that the society uses to represent an object. 


\section{CULTURE}

In according to Borhek and Curtis (1983) culture consists of learned as opposed to innate and shared as opposed to truly idiosyncratic ideas, and culturally constructed artifacts as opposed to physical artefacts. This definition of culture attributes the explanation for sharing of certain beliefs or ideologies to a certain kind of social process, that they take place in (SB). The process that accounts for the acquisition of culture by individuals is called socialization. It consists of regular schedules of reinforcement. At a simple level, the assertion that beliefs and ideologies are cultural rejects a whole range of possible alternative propositions. Culture has the following characteristics:

1) Culture implies a peculiar WV. Culture creates GCC.

2) Culture is patterned. It consists of related, not discrete elements, which are organized according to some general pattern. To move a trait from one culture to another is usually to change its function and significance through reinterpretation. This involves placing the trait within a novel context of meaning. Humans often communicate about WV as if it was a separate particle and recognize the need for context only when communication fails. The internal consistency of culture often escapes notice; it becomes apparent only when it is violated.

3) Culture provides orientation. Culture is used by humans, individually and collectively, as the primary source of solutions to the problems of orientation, and may provide solutions to substantive problems, according to which problems may be met with traditional and acceptable solutions. The existence of one or more orientations is often so implicit that the people involved would not ordinarily recognize them without being prompted.

4) Culture changes in response to pressure of events but only very slowly because it is to a degree systemic. If culture is systemic, this means that all WV's elements (goals, norms, values, and orientations) are linked and that a change in one has strong but subtle implications for change in others. As a set of solutions to substantive problems, culture is subject to immediate pressures for change. Besides providing in the first place the 
basic tools for any thought, feeling, judgement, or action, culture includes specific deontical norms (prescriptions and proscriptions), sets of rules on what to think, feel, and do. When these norms fail to solve practical problems, some alternative must be sought at once. Norms and values change less rapidly than technology. This is known as culture lag (Ogburn, 1950). Commitment to deontical norms and values is stronger than commitment to technology, in part because the technology is more closely geared to daily necessity.

5) Culture is differentiated into subcultures which are coextensive with networks of communication. Culture is coextensive with a network of communication. If societies consisted of homogenous collections of individuals, each communicating equally with all the rest, both, culture (and its peculiar GCC) and society would be undifferentiated units. Then, the conditions of Note 1 would be fulfilled. Since societies are differentiated, cultures are too, and along the same lines. That is to say, there are multiple $\mathrm{PCC}_{\mathrm{s}}$. Then $G C C=\bigcup_{i=1}^{n} P C C_{i}$. Neither societies nor the cultures they carry are as simple as a set of discrete building blocks. Each member of society participates in a somewhat different set of cultural "worlds", forming a particular IC, each consisting of shared meanings and extending as far as system of communication can support it (Manis and Meltzer, 1972). None of these cultural worlds (PCC) is the exclusive domain of a single human group. However, insofar as the boundaries of one kind of world are the same as the boundaries for another kind of world, a single group tends to emerge with that unique combined culture. That is to say, if we have a human group with $\mathrm{PCC}_{1}$ and another with $\mathrm{PCC}_{2}$, then $P C C_{3}=\bigcup_{i=1}^{2} P C C_{i}$. To the extent that major social cleavages are congruent with a whole list of communicative worlds, of course, the possibility of communication across the line of cleavages are lessened, subcultural distinctiveness is enhanced, and conflicts are likely to be acute. Communicative barriers, consisting, in turn, of barriers to social interaction, are cultural barriers. Cultures, as 
well as societies, are highly differentiated. Each participant in a subculture $\mathrm{PCC}_{\mathrm{i}}$ has a unique perspective based on his unique social position, interest, experience and PCC available to him. These members do not participate in exactly the same parts of the subculture, that is to say $P C C \neq \bigcup_{j=1}^{m} I C_{j}$. In consequence, the individual member is not identical with the subculture, and the believer is not identical with the WV. To be sure, the total subculture is carried by the network of communication in which the total set of individual members participates and may not be said to exist apart from the network of interactions. Nevertheless, each individual member's participation is specialized, and most participants devote far less than their full time to the activity, whatever it is (Borhek and Curtis, 1983). Applying this to belief systems belonging to a determinate $\mathrm{WV}$, the vast majority of believers are in rather substantial ignorance of the fine points of most belief systems in which they participate. Thus, culture derives a kind of transindividual power from its group expression; it does consist of something more and greater than is available to any one individual participant (Durkheim, 1965).

6) All societies are differentiated. Social differentation is a concomitant of institutional differentation which consists of the specialization and routinization of activities in general. In relative undifferentiated societies (see Note 1), a single social structure is used to organize all collective activities that need to be organized: work, religion, war, art, education and so on. It implies a peculiar and monolithic GCC. This social structure usually assigns positions to individuals based on age, sex, and descendance, creating therefore a restricted PCC and IC is confused generally with PCC. The kinship system is the basis for organizing any activity. Highly differentiated societies perpetuate certain bodies of knowledge and belief through such generalized structures as families, public schools, mass media, internet, etc. But in addition they also use highly specialized structures, such as professional associations, universities, theological schools, laboratories, etc. As activities develop 
in specialities, special purpose structures arise to organize them. The extent of institutional differentiation is of primary importance as a social condition affecting the culture carried by a society (Durkheim, 1947).

\section{DENOTATION AND CONNOTATION}

A semiologic theory of the ideologies must incorporate these concepts of an extended way, because when we spoke of ideology, in its different meanings, it implies a vision of Reality co-divided between many Subjects and limited by the society. Therefore, these visions of the world are not like subsystems of a global semantic system, that is to say, not segmented realities. In this sense, ideology is to us like an extra-semiotic reminder that determines the semiotic events.

Peirce (1933-1935) when solving the problem of meaning by the mediation of the interpretant gave an incomplete explanation, somewhere between an empiricist and a metaphysical explanation to the meaning process. A cultural unit can be a person, place, thing, feeling, situation, fantasy, hallucination, idea, hope, custom, etc. It is not only individualized by mediation through the flight of interpretings. The cultural unit is defined as "place" in a system of other opposed cultural units that circumscribe it. A cultural unit subsists and it is recognized in the measure in which "other" exists and "other" has a different value. It is the relation between several terms of a system of cultural values -what prevails to each one of them has something contributed by others (Eco, 1968). Like in a chess game, each piece acquires some value by the position that it has with respect to others and each disturbance in the system changes the sense of the other correlated pieces.

Definition 2: The semantic field is a structure that formalizes the units of a certain culture constituting a portion of the vision of the Reality that owns this culture.

Definition 3: The existence of information is independent of the fact that there is a Subject able to decode the message that someone is attempting to communicate. This information is termed significant and we denote as $\mathrm{a}$.

Definition 4: The information in a message acquires meaning if a Subject decodes the message. This subjective information is termed significance and we denote as $s$. 
Let SB be the conditions of life (Structural Base) (Usó-Domenech and NescolardeSelva, 2012), let $\mathrm{s}$ be the units of perceived experience (p-significances), let $\mathrm{u}$ be the corresponding cultural units and let $\square$ be the significant forms denoting $\mathrm{s}$, then we have the following extrasemiotic problems:

1) SB determines s giving rise to $u$ assigning the name of $\boldsymbol{\Xi}$.

2) SB requires $a$ to segment the experience in $s$, that corresponds to $u$.

3) A deep semiotic activity leads the human being to think with $\square$, which not only gives rise to $\mathrm{u}$ and $\mathrm{s}$, but that in addition requires the human being to prove the exigencies of $\boldsymbol{\Xi}$.

It is important to be aware that two or more semantic fields can coexist in the same culture and that a semantic field may dissolve to give rise to another one. In agreement with Eco (1968), we can affirm that:

a) In a certain culture, contradictory semantic fields may exist.

b) A single cultural unit can comprise of complementary semantic fields. A single cultural unit could occupy different positions in different semantic fields without incompatible classifications. For that reason it is important to admit that the user of any language has the possibility of providing to any objective system (significant), diverse systems of significances.

c) In a single culture, a semantic field may easily be undone and be reconstructed in a new field.

Consequence 1: The significance $s$ is a cultural unit, both in categorematical an noncategorematical terms.

Consequence 2: Semiotic systems are not synonymous or equivalent and similarly systems based on different units cannot describe each other. Descriptions require the same cultural units. A semiotic system can only be described when the elements that 
comprise it are known. It is impossible to describe a semiotic system using elements from a different system.

We may affirm that (Usó-Domenech and Nescolarde-Selva, 2012):

1) The significance $s$ is a cultural unit $u$.

2) This cultural unit $u$ can be individualized due to the linking of its interpreters, as it is pronounced in a concrete culture.

3) The study of the signs in a culture allows defining the value of the interpretant as in a system of positions and oppositions.

4) It is not possible to formulate a Global Semantic Field, that is to say, the formalization of the WV of a culture, because its peripheral interconnections and manifestations, changes constantly.

5) The semantic fields are postulated like useful instruments to explain the significant oppositions of a particular group of messages.

Let $\boldsymbol{a}$ be a significant and $\mathrm{s}$ be their significances (Usó-Domenech and NescolardeSelva, 2012). For each significant $\boldsymbol{\Xi}_{\mathbf{i}}$ exists a finite number of significances so that $\boldsymbol{\Xi}_{\mathbf{i}}$ $\rightarrow s_{1} \cup s_{2} \cup \ldots \cup s_{n}=\bigcup_{i=1}^{n} s_{i}$. If $s_{i} \equiv u_{i}$ then $\mathbf{\Xi}_{\mathbf{i}}=\bigcup_{i=1}^{n} u_{i}$. If during the period $\left\lfloor t_{\alpha}, t_{\beta}\right\rfloor$ of a culture exist $m$ significant $\boldsymbol{\Xi}_{\mathbf{i}}$ that can be interpreted, then

Definition 5: We may define as semantic field $\boldsymbol{乃}=\left\{\bigcup_{j=1}^{m} \mathbf{\Xi}_{\mathbf{i}} \rightarrow \bigcup_{j=1}^{m} \bigcup_{i=1}^{n} u_{j i}\right\}$.

According to Seimas (1970), we define semantic structure as:

Definition 6: By semantic structure we must understand the general form of organization of diverse semantic fields of a social and individual nature (culture or personalities).

Definition 7: We define denotation as the literal, obvious definition or the common sense of the significance of a sign. 
Denotation may be defined as the elementary modality of significance alleged by the referential mode. Let us talk about denotation of an isolated e.g., lexeme 1. A lexeme, like a morphologic unit, is associated with a certain cultural unit $\mathrm{u}$. The definition of Shannon (Shannon and Weaver, 1949) considers denotation without appealing to the referential mode and can be understood like the invariant in translation processes, that is to say, the significance of a significant, what stays as meaning if the significant changes. Nevertheless, it is impossible to apply this definition to an isolated lexeme. To do this, it would be necessary for the semantic fields of different cultures to be isomorphs. Therefore, we will have to understand denotation as the immediate reference that a term or concept causes in the adressee of the message. Therefore:

Consequence 3: Denotation is the immediate reference that the code assigns to a term or concept in a certain culture.

Consequence 4: The isolated lexeme denotes a position in a semantic system.

In Eco (1968) the notion of denotation is equivalent to ex-tension. The term or concept, besides specifying a class of real objects, denotes a set of cultural units $\left\{u_{i}\right\}$ occupying a particular position within a semantic field $\mathbf{b}$, with the exception that the class has only a member. Lexeme denotes the set of all those cultural units in different semantic fields, belonging to different cultures, occupying the same position in any semantic field. But this would demand that the semantic fields were isomorphs.

Let $\mathrm{C}$ be a culture and Љ be its semantic field. We denoted as $\mathrm{n}$ the respective position of a cultural unit $\mathrm{u}$ in the semantic field $\boldsymbol{~} \mathbf{b}$. We suppose as $C_{1}, C_{2}, \ldots, C_{\omega}$ different cultures with their respective semantic fields $\boldsymbol{\mathbf { b }}_{\mathbf{1}}, \boldsymbol{\mathbf { b }}_{2}, \ldots, \boldsymbol{\mathbf { b }}_{\boldsymbol{\omega}}$, Then $l=$ $\boldsymbol{\mathbf { b }}_{\mathbf{1}} \bigcap \boldsymbol{\mathbf { b }}_{\mathbf{2}} \bigcap \ldots \cap \boldsymbol{\mathbf { b }}_{\boldsymbol{\omega}}=\left\{u^{n}\right\}_{i=1,2, \ldots, \omega}$.

When the semantic fields are isomorphs (real condition), the units of a field are compared with others by mediation of proofs of commutation (verifying if changing a significant changes the contextual significance) or by proofs of substitution (it is verified if changing a significant means the significance does not change). Then: 
Definition 8: The denotatum of a lexeme lis its semantic bond in a determined semantic field Љ belonging to a certain culture $C$.

Lexeme 1 can assume different positions in diverse and complementary semantic fields

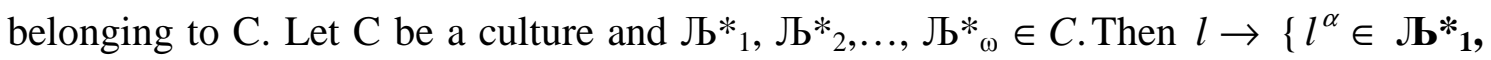
$\left.l^{\beta} \in \boldsymbol{乃}^{*}{ }_{2}, \ldots ., l^{\omega} \in \boldsymbol{乃}^{*}{ }_{\omega}\right\}$ being $\alpha, \beta, \ldots, \omega$ different positions.

Consequence 5: The significance s of lexeme l cannot be individualized in any context and with the aid of the circumstances of communication.

It is understood that all sequences of the interpretant through which the semiosis process revive lexeme 1 and makes it practicable, rests on the connotation.

Definition 9: Connotation is the sum of all the cultural units that the significant can evoke institutionally in the mind of the addressee Subject whose only psychic possibility is cultural availability.

In according to Eco (1968) diverse interpretations of connotation exist. We will mention those that we considered more important for our intention.

1) Connotation is like definitional meaning: Everything lexeme 1 connotes the properties attributed to the cultural unit denoted by the in-tensional definition that commonly is applied. Let us suppose the definition of /stars/. It can be ingenuous (famous personage of cinematography) or scientific, given in astronomic or astrophysical terms. Since in a same culture both forms of definition exist, even other intermediate ones, the possession of one or another form constitutes the cultural patrimony of the addressee subject.

2) Connotation of the semantic units that compose the significance: Some of these semantic components comprise the cultural unit, others do not. A named cultural unit can connote its own syntactic mark. In a fable or myth, where the objects are animated, these connotations have semantic value.

3) Emotional connotation: In agreement with Stevenson (1944) the emotional meaning is a significance in which the reaction or stimulus of the receiving 
Subject is an emotion. The touching or emotional connotation is an absolutely idiosyncratic fact. When one institutionalizes, the emotional connotation stops being "Vorstellung" (Frege, 1892), that is to say, a personal image due to the preceding experiences influenced by feelings. Then, the preceding socialized experiences become elements of the code. In big human groups, these elements are associated with a series of emotional connotations justified by a series of interpretations of the denotation. The measure of the meaning (Osgood, Succi and Tannebaum, 1957) will be the empirical way to be able to reveal the degree of institutionalization of the emotional connotations associated to the semantic stimulus.

4) Ideological definitions: They are incomplete definitions putting the cultural unit on approval or a complex of cultural units under one of their possible aspects. It is the "Sinn" of Frege (1892), or the cultural way in which the object is meant.

5) Global axiological connotations: A chain of connotations can assume for the adressee subject positive or negative values. These terminal axiological marks are the final connotations of the connotations and come bound to the semantics of ideologies.

Then and for our purpose:

Definition 10: The connotation of socio-cultural and individual associations, are the ideologies derived from the belief systems, and the emotional ones belonging to the psychology of the Subject, and that is the indirect function of the Semiotic Environment (context) in which is immersed.

A significant $\mathbf{a}$ can connote diverse significances $\left\{s_{i}\right\}$ (Usó-Domenech and NescolardeSelva, 2012), even sometimes in reciprocal opposition. To know to which of these significances connotes the significant $\boldsymbol{\Xi}$, in a determined context, is equivalent to say that the selection made by the issuer or the adressee is well-known. The selection consists of identifying different and complementary positions within different semantic fields belonging to a same culture. Due to the system of dual thought the human being owns, this selection will take place through oppositions. 
The significance $s$ tends to be multiplied from an individual sign, until it is equipped with many meanings that go beyond what the sign says now. Different orders of meaning or levels of significance exist:

1) The first order of significance is exactly the one of the denotation, in whose level there a sign $t$ consisting of significant $\mathrm{D}$ and a denotative significance $\mathrm{d}$-s.

2) The connotation is a significance of second order or c-s that uses the denotative sign $t$ (with significant $\mathrm{D}$ and denotative significance d-s) like its significant, with an additional associate significance.

This distinction considers the connotation as a sign that is derived from significant $\boldsymbol{\square}$ of a denotative sign d-t, so that the denotation takes us to a chain of connotations. Denotation is an underlying and primary significance d-s.

Consequence 6: The significant or significance $s$ depends entirely on the level in which the analysis operates. Then, what is significance s in one level of the context, can be significant $\mathbf{a}$ in another one.

Subject S receives two types of semiotic stimuli:

a) Significants from Subject S's own process or being.

b) Significants from the transmitted semiotic stimulus or significant of the significance (connotation).

We distinguish two types of significant (Usó-Domenech and Nescolarde-Selva, 2012):

Definition 11: The A-significant (A- $\mathbf{a})$ or first order significant is the significant that is inherent to the beings, processes or phenomena of the referential context.

Definition 12: The B-significant (B- $\mathbf{a})$, second order significant or connotation is the significant of significance $s$. 
Connotation B-口 has a veritative value $v^{\prime}(B-\Xi)=1$, having simultaneously, a relative veritative value or connotative veritative value $v(s) \in[0,1]$.

Consequence 7: Changes in the form of the significant a can generate different connotations.

Consequence 8: All B-significant B- מincluding in a context, will be denotative, therefore, they will have for the Subject a denotative veritative value equal to 1 .

Note 2: A denotative significance $d$-s is the significance of the absolute beings.

Note 3: The concept of denotative significance $d$-s agrees with the one of the relative beings.

Let $\boldsymbol{\Xi}$ be a significant. In a particular semantic field $\boldsymbol{\mathbf { b }}_{\mathbf{1}}$ denotes a significance $\mathrm{s}_{1}$ with a connotive position $\alpha$, it denotes a significance $\mathrm{s}_{2}$ with a connotive position $\beta$ in other semantic field $\boldsymbol{\mathbf { b }}_{2}^{*}$, it denotes a significance $\mathrm{s}_{3}$ with a connotive position $\beta \gamma$ in other semantic field $\boldsymbol{\mathbf { b }}_{3}$, and so on. This means that the significant $\mathbf{\square}$ deepens a series of ramifications in positions of diverse semantic fields. Let $\boldsymbol{\Xi}_{1}, \boldsymbol{\Xi}_{2}, \boldsymbol{\Xi}_{3}, \boldsymbol{\Xi}_{4}$ be a syntactic system of significant unities (Table 1).

Columns 3, 4 and 5 are semantic systems and sequence $\boldsymbol{\Xi}_{3}, s_{3}^{\alpha}, s_{3}^{\beta}, s_{3}^{\gamma}$ is a chain of connotations o connotative chain ל.

TABLE 1

\begin{tabular}{|c|c|c|c|c|c|}
\hline Significants & $\boldsymbol{\mathbf { b }}_{\mathbf{1}}$ & $\boldsymbol{\mathbf { b }}^{*_{2}}$ & $\boldsymbol{\mathbf { b }}_{\mathbf{3}}$ & $\begin{array}{c}\text { Connotative } \\
\text { chain }\end{array}$ \\
\hline $\mathbf{\Xi}_{\mathbf{1}}$ & & $s_{1}^{\alpha}$ & $s_{1}^{\beta}$ & $s_{1}^{\gamma}$ & \\
\hline $\mathbf{\Xi}_{\mathbf{2}}$ & & $s_{2}^{\alpha}$ & $s_{2}^{\beta}$ & $s_{2}^{\gamma}$ & \\
\hline $\mathbf{\Xi}_{\mathbf{3}}$ & $\rightarrow$ & $s_{3}^{\alpha}$ & $s_{3}^{\beta}$ & $s_{3}^{\gamma}$ & $\boldsymbol{\zeta}_{3}$ \\
\hline $\mathbf{\Xi}_{\mathbf{4}}$ & & $s_{4}^{\alpha}$ & $s_{4}^{\beta}$ & $s_{4}^{\gamma}$ & \\
\hline
\end{tabular}


When one isolated lexeme is combined with other lexemes we will obtain the following ramification (Figure 2):

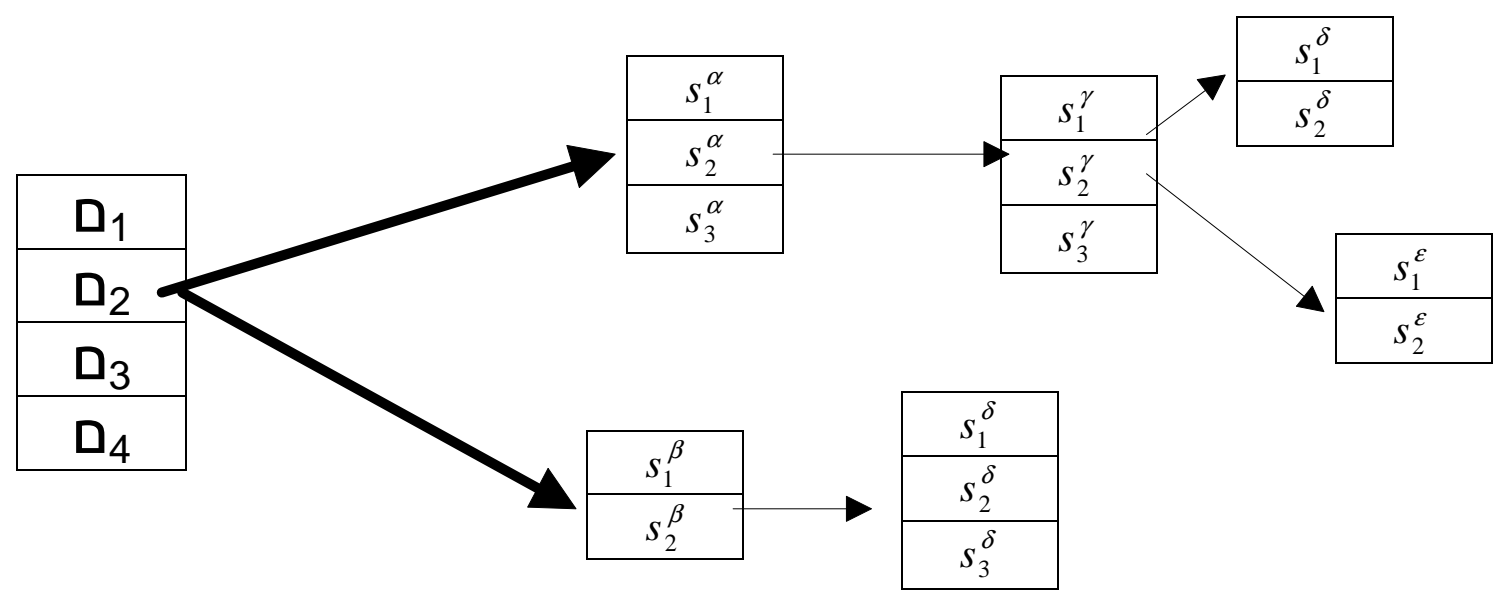

Figure 2.

In this scheme, assuming they form part of the code of a certain cultural community, the terminals of each ramification of the significant are considered like their semantic components (semantic markers).

Definition 13: The sense $\boldsymbol{\sigma}(\mathrm{Eco}, 1968)$ is a binary selection that the adressee Subject of a sentence makes between the diverse ramifications that compose the lexeme.

If the meaning (significance) of lexeme is the set of its denotation and connotations, the attributed sense is a selective path constructed by affirmations and negations.

\section{SEMIOTIC OF IDEOLOGIES}

The multiplicity of codes and subcodes intersecting in a culture demonstrates that even the same message can be decodified from different points of view and appealing to diverse systems and conventions. The message is protected by the fundamental denotation of the significant, but different connotations can be attributed to it. In the last instance, the extreme possibility exists that the base denotative code is different for the issuer and the adressee, and the message can transmit a complete but different sense in both cases. This takes us to two fundamental problems: 
1) Conditions exist that allow decoding in one sense or another.

2) The message is affected by a certain indetermination that is itself a possible source of information.

Some factors orient towards the reading of the preceding phrase.

1) The reference to the Universe of Reasoning (Lyons, 1968).

2) The reference to an ideology, understood in a coarse way either as a certain form acquired by the preceding knowledge of the adressee, or a system of prevention and opinions, or a perspective of the universe.

3) The circumstance of the communication. If the phrase has been pronounced by a priest in the mass-media, their denotative significance and its different connotative senses can be individualized clearly. A series of circumstances orients the addressees to deduce the ideology of the issuer, and the subcodes to which one can make reference.

For that reason and in agreement with Eco (1968), it is admitted that the sign denotes the real objects, that is to say, the perceived objects.

Consequence 9: The circumstance appears as the reality set that blinds and determines the selection of codes and subcodes with its own presence.

Therefore, the process of communication, although it does not indicate the referential, develops as the referential process.

Definition 14: The circumstance is the complex set of material, economic, social, biological, ecological and physical agreements in which human beings communicate.

Let St be a statement (concept or sentence) and let $\mathrm{Cr}$ be a circumstance (UsóDomenech and Nescolarde-Selva, 2012). We suppose $\{S t\}_{i=1, \ldots, n}$ the set of all posible statements such that $S t \in\{S t\}_{i=1, \ldots, n}$ and $\{C r\}_{j=1, \ldots, m}$ the set of all possible circumstances 
such that $C r \in\{C r\}_{j=1, \ldots, m}$. Let $\{\sigma\}_{k=1, \ldots, w}$ be the set of all possible senses of all possible statements such that (Table 2)

TABLE 2

\begin{tabular}{|c|c|c|c|c|}
\hline STATEMENT & \multicolumn{4}{|c|}{ SENSE } \\
\hline & $\sigma_{1}$ & $\boldsymbol{\sigma}_{2}$ & ......... & $\sigma_{w}$ \\
\hline $\mathrm{St}_{1}$ & $\left(S t_{1}, \sigma_{1}\right)$ & $\left(S t_{1}, \sigma_{2}\right)$ & $\ldots$ & $\left(S t_{1}, \sigma_{w}\right)$ \\
\hline $\mathrm{St}_{2}$ & $\left(S t_{2}, \sigma_{1}\right)$ & $\left(S t_{2}, \sigma_{2}\right)$ & ............ & $\left(S t_{2}, \sigma_{w}\right)$ \\
\hline $\mathrm{St}_{3}$ & $\left(S t_{3}, \sigma_{1}\right)$ & $\left(S t_{3}, \sigma_{2}\right)$ & $\ldots \ldots \ldots$ & $\left(S t_{3}, \sigma_{w}\right)$ \\
\hline ......... & ......... & .......... & ........... & \\
\hline $\mathrm{St}_{\mathrm{n}}$ & $\left(S t_{n}, \sigma_{1}\right)$ & $\left(S t_{n}, \sigma_{2}\right)$ & ........... & $\left(S t_{n}, \sigma_{w}\right)$ \\
\hline
\end{tabular}

That is to say, it will be the Cartesian product $\{S t\}_{i=1, \ldots, n} X\{\sigma\}_{k=1, \ldots, w}$. We do not consider the improbability of many of these binary relations. If we introduce the circumstances, one will become a table of three dimensions, formed by triplete $\left(S t_{i}, \sigma_{k}, C r_{j}\right)$, corresponding to the double Cartesian product $\left(\{S t\}_{i=1, \ldots, n} X\{\sigma\}_{k=1, \ldots, w}\right) X\{C r\}_{j=1, \ldots, m}$. It indicates to us that:

1) In each statement $S t_{i}$ could be anticipated an arbitrary circumstance $C r_{j}$ as to attribute to $\left(S t_{i}, \sigma_{k}\right)$ an inverosimil sense.

2) And of the most ambiguous statement can be deduced a circumstance that attributes to it the most obvious sense.

Consequence 10: A statement will have an obvious or inverosimil sense depending on the circumstance.

1) The circumstance changes the sense of the message. For example: a red flag means danger on a beach, revolutionary ideology in a political manifestation or a pirate ship in an historical or adventure movie. 
2) The circumstance changes the function of the message. For example, the signalling of prohibition in a highway has a different emotional sense than in a parking lot.

3) The circumstance changes the degree of information. For example: the cross has an information degree different in the case of a believer, the sides of an ambulance or in a hospitable.

Nevertheless, the code inevitably takes part in limiting and classifying some possibilities and not others. Culture $\mathrm{C}$ classifies a series of frequent circumstances in which a statement (lexeme or sentences) acquires a possible meaning, that is to say, it has a sense. Therefore, it is the culture that takes part like a Recognoscitive Grammar ${ }^{1}$ in the semantics of statements, forming rules of circumstantial competence establishing that semantic path of connotations that must be followed and which cannot.

The intersecting intercrossing of circumstances and ideological data budgets, along with the multiplicity of codes and subcodes, requires that the message appears as a plastic form to which diverse senses can be attributed. Therefore, the information of a message (Shannon, 1949) will have to be processed by evaluating the wealth of possible and individualizable selections at the level of the message-significant. Information can be reduced when the message-significant is related to certain subcodes and it becomes message-significance, that is to say, in definitive selection executed by the adressee subject. Therefore, we will have two types of different information:

1) The information from the source: it is physical information, computable quantitatively, statistically equiprobable and reducible to the system like a correction of probabilístic terms and always open to different possibilities.

2) The semiotic information: noncomputable quantitatively but can be defined by mediation of the series of significances that can be generated from contact with the corresponding codes. It is not totally indeterminate, being reduced in a definitive way by the interpretation or selection of a concrete message.

\footnotetext{
${ }^{1}$ A generative grammar, as the name implies, builds the syntactically correct sentences of a language. But those words may have no meaning. A Recognoscitive Grammar selects phrases that have meaning (Y.Villacampa et al. 1999; F. Vives-Macia, 1999).
} 


\subsection{Message and codes}

The message opened to a multiplicity of codes and subcodes appears as a form that is empty of all sense, but from the point of view of the logic of significants, with a very precise organization. This organization is the one that orients the decoding and selection of the senses, exactly according to the ideology, circumstances or other extrasystemic factors.

We can establish two types of judgements in reference to the existing codes: semiotics and factuals (Eco, 1968).

Definition 15: The semiotic judgment is that in which the predicate is contained implicitly in the subject.

Definition 16: The factual judgment is that in which the predicate is added to the subject like a new attribute, due to a synthesis that takes place between the empirical data and a new form of thought.

A judgement is semiotic in the sense that it constitutes the statement of the intensities that a code attributes to a certain cultural unit $\mathrm{u}_{\mathrm{i}}$. Therefore a judgement is semiotic according to a convention and that when changing the convention, judgements that were semiotic turn factual and vice versa (White, 1950). This is in agreement with diverse authors (Austin, 1961; Quine, 1953)

1) A judgement is semiotic when its condition really depends on its significance.

2) A judgement is factual when its significance depends on a condition really given by a comparison with the empirical referential.

3) A semiotic judgement says what the code anticipates.

4) A factual judgement says what the code does not anticipate, and therefore enriches the code.

A factual judgment only has semiotic importance if it is admitted as true, independently of its verification or falsification. In the measure that it is accepted as true, the code enriches and it provides new connotations. Therefore a dialectic exist between codes and messages, thus the codes govern the issue of messages, but new messages can 
reconstruct the codes and this is proof of the creativity of the language and the dialectic between "creativity governed by rules" versus "creativity changing rules" (Chomsky, 1962). The factual judgement can be considered as a creativity allowed by rules with a code; the syntactic rules allow articulation of messages that enrich the senses of the different semantic units. A diachronic dimension is inserted in the synchronous dimension of the code as a system of subcodes altering its structure, following its dynamic possibilities and their combinatory capacity, as if the code tended to reconstruct itself continuously, but at superior level.

\subsection{Semiotic system and WV}

A semiotic system like WV is one of the possible ways of giving form to the world, and so, it constitutes a partial interpretation of this world, being able to be reviewed theoretically whenever new messages, reconstructing the code semantically, introduce new connotative chains $ל_{\mathrm{i}}$ and for that reason, create new attributions of value.

An ideology is a conceptualization or materialization of a WV. But conceptualization, crystallization, etc., once it has appeared, immobilizes the WV that gave origin it. Any ideology is crystallized immediately in a series of behaviors (rules, organized associations, cults, discipline, rituals, liturgies, etc.), that necessarily move away from the WV that was its origin. According to Ferreras (1980) WV never is crystallized, conceptualized; it exists in the society, in its Doxical Superstructure, being able to mediate a series of social behaviors and ways to relate, but its existence is only verified by its effects. There is not, then, "a presence" of the WV, but "a subjective or interior presence" and, of course, diffusely perceived, by the subjects of the same society that has generated or produced this certain WV. WVs mediate the deep and nonconscious homologíes between the effects (literary works, art, science, deontical rules, etc.) and the society. Nevertheless, ideologies not only mediate, but that explains the effects, and at the same time as explaining them, they close, in a certain sense, all ways to an explanation of these effects. Therefore, ideologies are historical crystallizations of a social class, group, and etc. conscience; like something already given and constructed (by the associations that carry them). The fact that many ideologies contain a high degree of falsification should not make us forget that history considers all types of WV as ideological, not that this invalidates the human need for fighting what is right. 
To define this partial $\mathrm{WV}$, this prospective segmentation of reality, is equivalent to define ideology like a false conscience (Marx and Engels, 1976). Naturally, this "false conscience" of the Marxist theory, arises as a theoretical camouflage from concrete social relations and certain material conditions of life. In this case, the ideology is a message that started off as a description, hypothesis, or a theoretical justification and gradually is seen by society like an element of the code. A semiotic theory of ideologies is not interested in knowing as it does not conceive the message nor its political or economic causes; however, it is interesting to know in what sense the new element of the code may be called "ideological".

\section{IDEOLOGICAL TRANSMISSION}

We restate here the theory of images and projections presented previously (UsóDoménech et al., 2009). We will denote as $s_{\Sigma}$ the denotative significance (dsignificance). We are going to suppose the existence of an only WV or an only ideology in the Ideological Doxical Superstructure (IDS).

Definition 17 (Usó-Domènech et al., 2009, Usó-Domenech and Nescolarde-Selva, 2012): For each d-significance $s_{\Sigma}$ exists an only one IDS-significance $\mathcal{E}^{D_{\Sigma}}$ that we will denominate as a doxical superstructural image (IDS-image) of $s_{\Sigma}$ in IDS.

However, at the same time the human adressee adds a connotative significance $c-s_{\Sigma}^{D}$.

Definition 18: Corresponding to each IDS-significance $s_{\Sigma}^{D}$ in IDS, will exist an only csignificance $c-\vec{s}_{\Sigma}^{D}$ to which we will call connotative-SB-projection (CSB-projection) of the IDS-significance $s_{\Sigma}^{D}$ in the structural base $(S B)$ and that $c-s_{\Sigma}^{D}=$ for each $\xi_{\Sigma}$ and for each $i_{\Sigma} \in I_{\Sigma}, i_{\Sigma} \in c-\overrightarrow{s_{\Sigma}^{D}}\left(\xi_{\Sigma}\right)$, iff $i_{\Sigma}^{C} \in s_{\Sigma}^{D}\left(\xi_{\Sigma}\right)$.

Note 4: Connotative significance $c-\vec{s}_{\Sigma}^{D}$ can simply be an only significance or a connotative chain $ל_{\mathrm{i}}$ of that the receiving subject only perceives its end.

A significant $\boldsymbol{a}$ denotes significance $s_{\Sigma}$. 
Note 5: With the existence of ideologies any message becomes or fixes formulae of connotation and blocks any critical process of meta-semiosis.

Nevertheless, it may be the case in that the meta-semiotized message is not possible, and that is the hypothesis of Sapir-Whorf (Sapir, 1921 and Whorf, 1956).

Hypothesis of Sapir-Whorf: The syntactic structure of a language L is the particular ideological network that imposes on the user a certain WV.

The selection of any code, given by connotations $c-{ }^{1} \vec{S}_{\omega}^{D}$ and $c-{ }^{2} \vec{S}_{\omega}^{D}$ can be determined by factors of practical order: the maximum of energy could be good having, even at the cost of degradation of the environment, or accepting insufficient energy before running the risk of an ecological catastrophe. This set of valuations constitutes the type of ampler recognition, and therefore, a new extra-semiotic remainder. Nevertheless, if it is socialized in SB, this remainder is again semiotically organized.

We are going to consider the SB in times $t_{n}$ and $t_{n+1}$ like two containers that we will denominate $\beta$ and $\alpha$ respectively. System $\beta-\alpha$ will be considered as the source of information, corresponding to the "phantasmagoric" referential, that is an extrasemiotical being, the message to communicate that things or events happen in $\beta$. Semiotics does not have to verify what happens in $\beta$, but must control if the messages referred to $\beta$ are grammatically correct. System $\beta-\alpha$ has been a system-code transmitting only certain information; it is playing the role of filter, a polarizing lens or Maxwell's demon. We have then the concept of doxical filter that we have previously presented. What represents the doxical filter in system $\beta-\alpha$ understood as a systemcode? It represents the ideology, which in this case has the structure of the code (Eco, 1968).

In system $\beta-\alpha$ two phenomena happen:

1) There exist units of significance imposed as pertinent by acquired experience.

2) There exists a syntactic structure of the code, which comes conditioned by the pertinent elements of the semantic system.

In Eco (1968), there are two possible answers for the structuration of the code: 
1) Only certain semantic units and not others are accepted as pertinent, and a code with certain syntactic structures prevails, and for that reason culture has determined the structure of the code.

2) Syntactic structure of the code proceeds to the individualization of the pertinent elements of meaning; then, the semantic system does not generate the syntactic structure of the code, but that happens inversely. Then, the WV is considered in terms imposed by the system of generative rules of the code. In this case, language $\mathrm{L}$ determines culture and not culture determines language. That is to say, the hypothesis of Sapir-Whorf prevails.

We think that both phenomena happen. Although language L determines culture (second option), the acquired experience accepts answers and not others, somehow modifying the syntactic structure of the code (first option).

A certain way to use a language $L$ is identified with certain way to think a society, with its WV. Therefore, we may say:

Definition 19: The semiotical ideology is the final connotation of the chain of connotations $ל$, or like the connotation of all the connotations of a lexeme.

\section{AN ECOLOGICAL CASE}

Let us suppose that the significance represents " $"$ " energy consumption" (UsóDomenech and Nescolarde-Selva, 2012). We will name $\alpha$ the signal "minimum of energy" and $\omega$ the signal "maximum of energy". Each one of these two signals would correspond to two denotative significances $s^{D}{ }_{\alpha}, s^{D}{ }_{\omega}$ that would correspond to two images $\varepsilon_{\alpha}, \varepsilon_{\omega}$ in IDS. The connotative projection of $\varepsilon_{\alpha}$ can suppose “ $c-\vec{S}_{\alpha}^{D}=$ minimum well-being" and the one of $\omega, " c-\vec{S}_{\omega}^{D}=$ maximum well-being". Why does a certain adressee chooses a connotation and not another alternative? Experience has taught him what $\alpha$ may be hoped from the denoted situation and the patrimony of knowledge has become stabilized. This cultural patrimony represents a extra-semiotical remainder until it becomes occasional or idiosyncratic, not communicating with anybody. However, without experience of being socialized, the cultural data happens to be an element of a 
semantic system, with a connotative subcode that establishes an imprisonment of prefixed references, mediated by denotation, so arriving at the connotation "suitable energy". The mechanism we can see in figure 3.

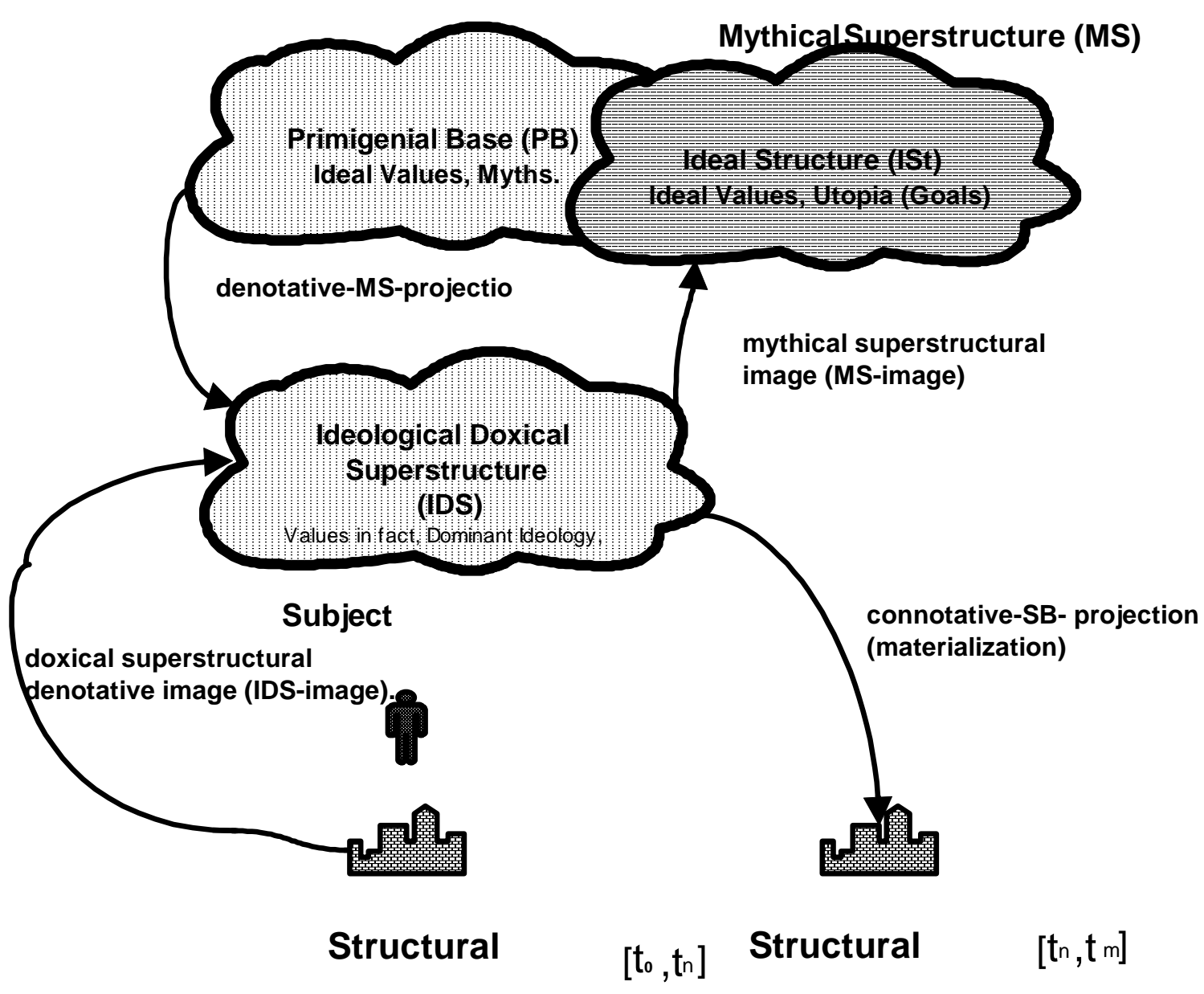

Figure 3.

Now let us suppose the case of two ideologies in IDS. We suppose the existence, in SB of two human groups, believing respectively in each one of the two ideologies (figure $4)$.

Nevertheless, signal $\omega$ may denote, according to the adressee "well-being" or "danger" (degradation of environment), being based on two equally legitimate codes. We have before a series of semantic systems at the secondary level that oppose values of the type "desirable versus danger". Each unit of these semantic systems " $c-{ }^{1} \vec{S}_{\omega}^{D}=$ maximum well-being" and "c- ${ }^{2} \vec{S}_{\omega}^{D}=$ danger" becomes the connotative significance of the 
significant " $\square=$ energy consumption" represented by the denotative significance $\varepsilon_{\omega}$ of the semantic system in the first level.

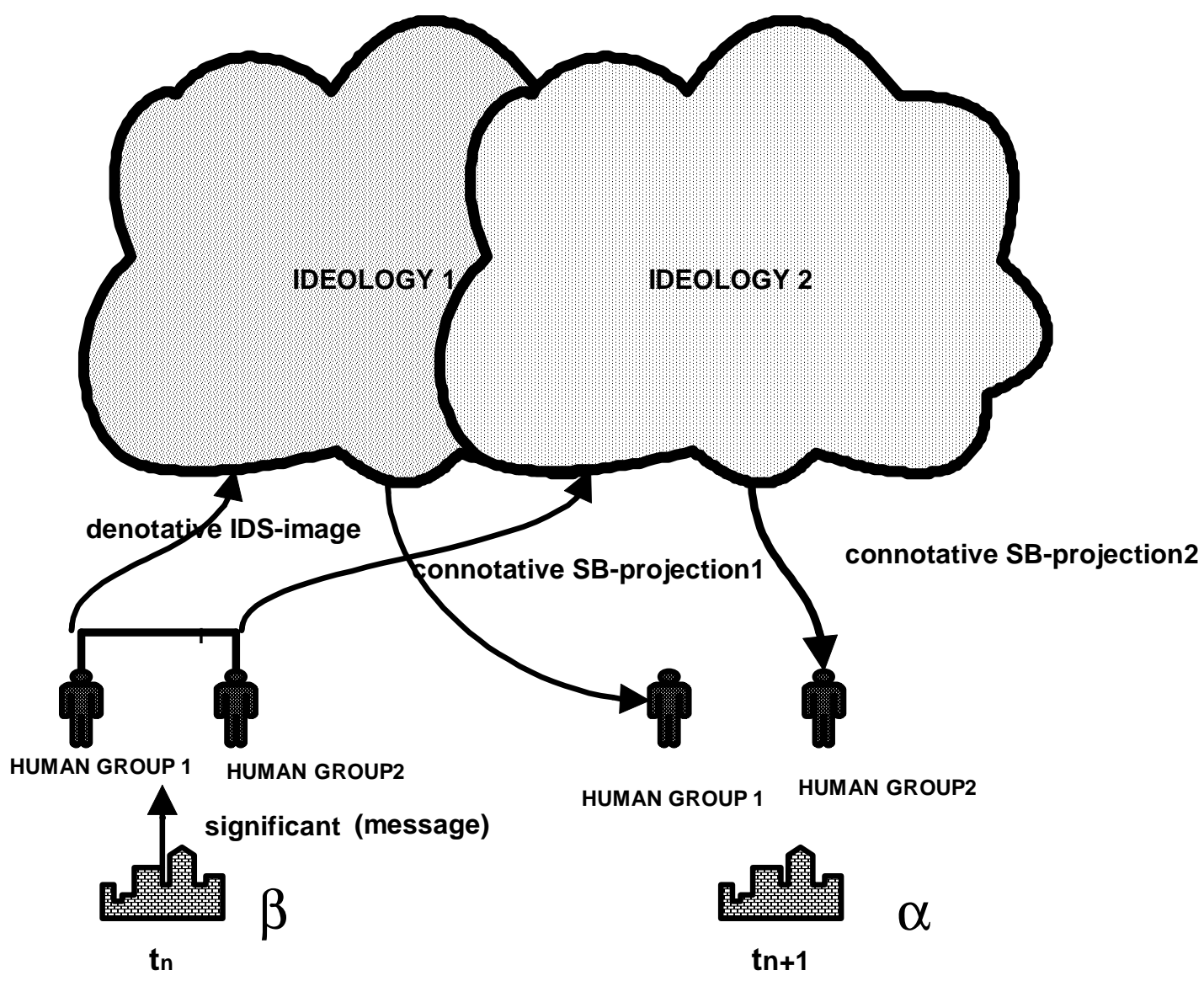

STRUCTURAL BASE

Figure 4.

Thus there may exist for a human group 1 a connotative code for $c-{ }^{1} \vec{S}_{\omega}^{D}$ that establishes /maximum energy/ = "maximum productivity" and an other that establishes /maximum energy/ = "maximum well-being society" and finally a subcode that establishes /maximum well-being of the society/ = "justification of any cost". And there may exist for human group 2 another connotative code for $c-{ }^{2} \vec{S}_{\omega}^{D}$ that establishes /respect for environment / = "elimination of all cost of unnecessary energy". These systems of values are semantic systems that sometimes are excluded mutually. When this is not the case, they can be included in a more complete code than offers transformation rules to translate the more restricted systems in terms of a more complete system. Now we 
suppose that somebody, belonging to human group 1, identifying message $\alpha$ with the connotation "well-being", uses it always in this way. Then, $\alpha$ becomes a symbol, it is the emblem of "well-being". The fixed connection between the significant " $\boldsymbol{q}=$ energy consumption" and Idea of Well-being acts metaphorically. Then we were before a rhetorical artifice or rhetorical figure. We do not consider the case that somebody, with a nonconfesable interest, issues message $\alpha$ when the situation denoted habitually by $\alpha$ does not take place in SB. In this case, we would have a falsification. In this falsification case, still it is not possible to speak of ideological use of a language L, with the meaning of ideology as a false conscience and camouflage (Eco, 1968). When message $\alpha$ becomes a rhetorical figure connoting "well-being" automatically, conscientious or unconsciously, the believers of human group 1 reject the possibility of applying the message, possibly with the connotation of "danger". Due to an ampler semiotical system, second connotation $c-{ }^{2} \vec{S}_{\omega}^{D}$ is equally foreseeable, but the use of the first connotation $c-{ }^{1} \vec{S}_{\omega}^{D}$, optimistic type, is imposed or induced, it gives to the message a fixed ideological function. The message has become an ideological instrument hiding the other relations. Then the ideology takes the function of a false conscience from the Marxist perspective. According to Eco (1968), from the semiotic point of view a message $\alpha$ exists that has happened to be a significant unit of a rhetorical subcode. This significant " $"=$ energy consumption" connotes a significance $c-{ }^{1} \vec{S}_{\omega}^{D}$ or a significance $c-{ }^{2} \vec{S}_{\omega}^{D}$, like a semantic unit of an ideological code. In this case, the message hides (instead of communicating) the material conditions that it had to express. In addition, this is because it has assumed falsifying functions by hiding the different semantic systems in the totality from its mutual relations.

In our system $\beta-\alpha$ two phenomena happen:

a) The units of significance = minimum of energy; maximum of energy are imposed as pertinent by the acquired experience.

b) The syntactic structure of the code is conditioned by the pertinent elements of the semantic system.

\section{REFLECTIONS}

A semiotic theory of systems derived from language would have the purpose of classifying all the systems of linguistic expression: philosophy, ideology, myth, poetry, 
art, as much as the dream, lapsus, and free association in a pluridimensional matrix where will be interfered many diversified fields. In each one of these discourses it is necessary, in effect, to consider a plurality of questions, that are systemically interrelated. It will be necessary to ask about, in the first place, what will be the purpose of this language, what function does it fulfil, and for what reason has it been constructed. All solutions to the problem of Doxical Superstructure (DS) depends on language's constitution, because this will allow us to differentiate the diverse discourses that man, as subject and actor, maintains based on exhaustive criteria defining, in part, each type of language, and in another part, isolating the "places" where it makes contact with other spheres of reality.

\section{REFERENCES}

Agazzi, E. Some Philosophical Implications of Gödel's Theorem. In: Kurt Gödel Actes du Colloque, Neuchâtel, 13-14 juin 1991. (Ed. Denis Miévill). Travaux de Logique, 7. 129-159. 1992.

Austin, J.L. The Meaning of a Word. In: Philosophical Papers. Clarendon Press. Oxford. 1961.

Borhek, J.T. and Curtis, R.F. A Sociology of Belief. Robert E. Krieger Publishing Company. Malabar. Florida. 1983.

Chomsky, N. Current Issues in Linguistic Theory. Ninth Int. Congress of Linguistic. Cambridge. 1962.

Durkheim, E. The Division of Labor in Society. The Free Press. New York. 1947.

Durkheim, E. The Elementary Forms of the Religious Life. The Free Press. New York. 1965.

Eco, U. La struttura assente. Casa Editrice Valentino Bompiani \& C.S.p.A. 1968. (In Italian)

Ferreras, J.I. Fundamentos de Sociología de la Literatura. Ediciones Cátedra, SA. Madrid. 1980. (In Spanish).

Frege, G. Über Sinn und Bedeuntun. Zeitschrift für Philosophie un philosophische Kritik, 100. 1892. (In German).

Lyons, J. Introduction to Theoretical Linguistics. Cambridge.University Press. 1968.

Manis, J.C. and Meltzer, B. N (eds). Symbolic Interaction: A Reader in Social Psychology. Allyn \& Bacon, Inc. Boston. 1972. 
Marx, K. and Engels, F. The German Ideology. Moscow: Progress Publishers, 1976 [c. 1845]).

Meinong, A. Über Gegenstandtheorie. Leipzig. J.A. Barth. 1960 [1904]. (In German).

Ogburn, W. F. Social Change. Revised edition. The Viking Press, Inc. New York. 1950.

Osgood, Ch., Succi, G.J. and Tannebaum, P.H. The Measurement of Meaning. Urbana: University of Illinois Press. 1957.

Peirce, C. S. Collected Papers of Charles Sanders Peirce, vols. 1-8, C. Hartshorne, P. Weiss y A. W. Burks (eds.). Cambridge, MA: Harvard University Press. 1931-1958.

Quine, W. V. O. From A Logical Point of View. Harvard University Press. Cambridge. 1953.

Shannon, C.E. and Weaver, V. The Mathematical Theory of Information. Urbana. University of Illinois Press. 1949.

Sapir, E. Language. Harcourt Brace. New York. 1921.

Sastre-Vazquez., P., J.L. Usó-Domènech, Y. Villacampa, J. Mateu and P. Salvador. Statistical Linguistic Laws in Ecological Models. Cybernetics and systems : An international Journal. Vol 30(8). 697-724. 1999.

Stevenson, Ch. L. Ethics and Language. New Haven. Yale University Press. 1944

Usó-Domènech, J.L. and Villacampa, Y. Semantics of Complex Structural Systems: Presentation and Representation. A synchronic vision of language L(MT). Int. Journal of General Systems, 30(4), 479-501. 2001.

Usó-Domènech, J.L., G. Stübing, J. López Vila, and P. Sastre Vázquez. Comportamiento de Arbustos Pirófitos en el Paraje Natural Desert de les Palmes.(Prologue by B.C. Patten) Edita Fundación Dávalos-Fletcher. Castellón de la Plana. 2002. (In Spanish)

Usó-Domènech, J.L., J. Mateu. Teoría del Medio Ambiente: Modelización. Publicaciones de la Universitat Jaume I. Colección Medio Ambiente. Vol3. 2004. (In Spanish)

Usó-Domènech, J.L., Vives-Maciá, F., Nescolarde Selva, J. and Patten, B.C. A Walford 's metadynamic point of view of ecosustainability ideology (II). INTERSYMP. 2009.

Usó-Doménech, J.L., Nescolarde-Selva, J. Mathematic and semiotic theory of ideological systems. Editorial LAP. Sarrebruck. Germany. 2012.

Villacampa, Y., Usó-Domènech, J.L., Mateu, J. Vives, F. and Sastre, P.. Generative and Recognoscitive Grammars in Ecological Models. Ecological Modelling. 117, 315-332. 1999. 
Villacampa-Esteve, Y., Usó-Domènech, J.L., Castro-Lopez-M, A. and P. SastreVazquez. A Text Theory of Ecological Models. Cybernetics and systems: An International Journal. Vol. 30(7). 587-607. 1999.

Vives-Macia, F. Sintaxis y codificación en modelos de Sistemas Complejos. Doctoral thesis. University of Alicante. 1999

White, M. The Analytic and the Synthetic: An Untenable Dualism. John Dewey. (Ed. S. Hook). Dial Press. New York. 1950.

Whorf, B.L. Language, Thought and Reality. Ed of J. B. Carroll, MIT Press. Cambridge. 1956.

Wilber, K. The Spectrum of Consciousness. 1977. 20 ${ }^{\text {th }}$ Anniversary Edition. Quest Books. 1993. 